Mechanical Engineering \& Computer Science

\author{
Electronic journal
}

http://www.technomagelpub.ru ISSN 2587-9278
Mechanical Engineering and Computer Science, 2018, no. 09, pp. 15-33.

DOI: 10.24108/0918.0001412

Received:

30.08 .2018

\title{
Computational Experiments to Evaluate the Approaches to the Modeling of Viscoelastic Plates Motion Based on Various Theories
}

B.A. Khudayarov ${ }^{1, *}$

\author{
bakht-flpo@yandex.ru \\ ${ }^{1}$ Tashkent Institute of Irrigation and Agricultural \\ Mechanization Engineers, Tashkent, Uzbekistan
}

\begin{abstract}
Generalized mathematical models of non-linear problems of the flutter of viscoelastic isotropic plates, streamlined by a supersonic gas flow, are constructed in the paper on the basis of integral models. To study oscillation processes in plates, a numerical algorithm is proposed for solving nonlinear integrodifferential equations with singular kernels. Based on the developed computational algorithm, a package of applied programs is created. The effect of the singularity parameter in heredity kernels on the vibrations of structures with viscoelastic properties is numerically investigated. In a wide range of changes in plate parameters, critical flutter velocities are determined. Numerical solutions of the problem of viscoelastic plate flutter are compared for different models. It is shown that the most adequate theory for investigating a wide class of problems of the hereditary theory of viscoelasticity is the geometric nonlinear Kirchhoff-Love theory with consideration of elastic waves propagation. It is established that an account of viscoelastic properties of plate material leads to $40-60 \%$ decrease in the critical flutter velocity.
\end{abstract}

Keywords: mathematical modeling, viscoelasticity, numerical method, computational algorithm, integro-differential equations, flutter, critical velocity

\section{Introduction}

Mathematical and computer modeling of the flutter of elements and units of the aircraft design is an actual scientific problem; its study is stimulated by the failure of aircraft elements, parts of space and jet engines. In view of the complexity of the flutter phenomenon of aircraft elements, simplifying assumptions are used in many studies. However, these assumptions, as a rule, turn out to be so restrictive that the mathematical model ceases to reflect the real conditions with sufficient accuracy. Therefore, results of theoretical and experimental studies are in bad agreement.

At present, the problem of panel flutter is very relevant. Improvement of characteristics of military and civil aircraft inevitably requires reducing their weight, and consequently, the rigidity of paneling, which increases the possibility of a panel flutter. The concept of creating the aircraft with a variable shape, which would inevitably lead to a reduction in paneling thickness are ac- 
tively discussed. Finally, the use of new materials and, in particular, composites, changes physical properties of the panels and can also lead to a flutter.

Among the problems of mathematical modeling of a flutter, an extensive class of problems is singled out - the problems of a panel flutter, in the formulation of which a streamlined body can be considered as a plate or a flat shell. In known studies of the nonlinear panel flutter, the Karman equations are used to model the strain of a plate. Their conclusions are based on the Kirchhoff hypotheses. In [1] a study of nonlinear panel flutter is considered. The equations of motion are obtained on the basis of the Karman nonlinear theory. Aerodynamic pressure is calculated according to the piston theory.

In $[2,3]$, oscillations of thin infinitely long rectangular plates at different flow rates are studied. The equations of motion are obtained on the basis of the Karman nonlinear theory.

In [4], the behavior of isotropic plates under the effect of supersonic gas flow is investigated. The pressure on the plate surface is taken into account according to the piston theory up to the third order. It is shown that the behavior of thin plates is influenced by high-speed flows that provide an amplitude-frequency relationship that describes nonlinear oscillations of aeroelastic system under consideration.

A great number of studies have been devoted to flutter instability of plates and shells [5 17]. In [18] Marco Amabili presents an extensive review of published papers on the flutter of plates and shells found in various scientific journals in 2003-2013.

Wide application of composite materials in aviation technology has led to the need to study the problems of optimal design of thin-walled structures with viscoelastic properties. In accordance with this, an analysis of specific features with respect to similar problems for elastic thinwalled structures is of considerable interest. Such an analysis is interesting and important because the presence of damping properties in viscoelastic material can be sufficient to prefer them when creating appropriate thin-walled structures from material with required properties.

The first mathematical models for studying viscoelastic plates have been constructed by V.I. Matyash [19] and G.S. Larionov [20]. The flutter of the plate is investigated using the average method.

In most studies, in research of non-linear problems in the dynamics of elastic and viscoelastic systems, for the sake of simplicity, it is assumed that dynamic process can be considered without elastic waves propagation. In this case, it becomes possible in the equations of motion to discard the tangential inertia terms with respect to displacements. Calculations show that the systems of equations with respect to deflection solved under these assumptions, the stress and angular displacements functions in many cases give satisfactory results. However, under certain physic mechanical and geometric parameters, dynamic processes occur in the shells in which the account of elastic waves propagation is necessary. In [21] nonlinear oscillations of viscoelastic plates are investigated. Modeling of elastic element motion is based on dynamic geometrically nonlinear equations of shell theory obeying the Kirchhoff-Love hypothesis, not accounting elastic waves propagation. However, the limits of applicability of these assumptions are not determined there. The Kelvin-Voigt model is used to describe the effects of viscoelastic material. In 
[22] the Kelvin-Voigt model is used for theoretical description of viscoplastic properties of structure material.

The main dependencies related to viscoelastic plate and shell models, based on the Kirchhoff-Love hypothesis, are presented in [23, 24, 25]. The use of these models allows to achieve sufficient accuracy in solving a number of practical problems.

The problem of the flutter of viscoelastic plates and cylindrical panels with concentrated mass is considered in [25]. In the equation of motion of a plate and panel, the influence of concentrated mass is taken into account using the Dirac $\delta$-function.

In the study of elastic and viscoelastic plates in a gas flow, various nonlinear equations of motion are applied in a simplified model. Equations in general models represent significant mathematical and computational difficulties. This makes it difficult to compare the solutions of the flutter plate problem by different models.

With the proposed numerical method [26-28], for the first time in a viscoelastic statement it became possible to compare the results of various theories (B - Berger, K-L-1- Kirchhoff-Love (not considering elastic wave propagation), K-L-2 - Kirchhoff-Love (considering elastic wave propagation) (Table 1). The use of the Kirchhoff-Love model (not considering elastic wave propagation) and Berger model make it possible to obtain fairly accurate solutions of a number of practical problems, but in most cases they are not complete enough. So, there rises a necessity to determine the applicability limits of different theories in solving the problem of a flutter of viscoelastic plates in geometrically nonlinear statement.

In this paper, based on integral models, generalized mathematical models of non-linear problems of the flutter of viscoelastic isotropic plates streamlined by a supersonic gas flow are constructed. For the study of plates based on the Marguerre theory of flat shells [29], mathematical models have been constructed with reference to the study of the problems of strength, rigidity and stability of thin-walled aircraft structures. Aerodynamic pressure is calculated in accordance with the piston theory [30].

\section{Equations of motion of a viscoelastic plate in a supersonic gas flow and their solution}

Consider nonlinear problem of a flutter of viscoelastic plate. Let the plate with sides $a$ and $b$ and thickness $h$ be hinged along the whole contour, streamlined on one side by a supersonic gas flow.

According to the general models (K-L-2), the system of equations of vibrations of viscoelastic plates streamlined by a gas flow is described by equations

$$
\begin{aligned}
& \left(1-R^{*}\right)\left\{\frac{\partial^{2} u}{\partial x^{2}}+\frac{1-\mu}{2} \frac{\partial^{2} u}{\partial y^{2}}+\frac{1+\mu}{2} \frac{\partial^{2} v}{\partial x \partial y}+L_{1}(w)\right\}-\rho \frac{1-\mu^{2}}{E} \frac{\partial^{2} u}{\partial t^{2}}=0, \\
& \left(1-R^{*}\right)\left\{\frac{\partial^{2} v}{\partial y^{2}}+\frac{1-\mu}{2} \frac{\partial^{2} v}{\partial x^{2}}+\frac{1+\mu}{2} \frac{\partial^{2} u}{\partial x \partial y}+L_{2}(w)\right\}-\rho \frac{1-\mu^{2}}{E} \frac{\partial^{2} v}{\partial t^{2}}=0, \\
& D\left(1-R^{*}\right) \nabla^{4} w+L_{3}^{*}(u, v, w)+\rho h \frac{\partial^{2} w}{\partial t^{2}}=q .
\end{aligned}
$$


Here $D=\frac{E h^{3}}{12\left(1-\mu^{2}\right)}$ - is the rigidity at bending; $\rho$ - is the density of material; $h$ - is the thickness of the shell; E - is the modulus of elasticity; $\mu$ - is the Poisson ratio;

$$
\begin{gathered}
L_{1}(w)=\frac{\partial w}{\partial x} \frac{\partial^{2} w}{\partial x^{2}}+\frac{1+\mu}{2} \frac{\partial w}{\partial y} \frac{\partial^{2} w}{\partial x \partial y}+\frac{1-\mu}{2} \frac{\partial w}{\partial x} \frac{\partial^{2} w}{\partial y^{2}} \\
L_{2}(w)=\frac{\partial w}{\partial y} \frac{\partial^{2} w}{\partial y^{2}}+\frac{1+\mu}{2} \frac{\partial w}{\partial x} \frac{\partial^{2} w}{\partial x \partial y}+\frac{1-\mu}{2} \frac{\partial w}{\partial y} \frac{\partial^{2} w}{\partial x^{2}} \\
L_{3}^{*}(u, v, w)=-\frac{E h}{1-\mu^{2}} \frac{\partial}{\partial x}\left\{\frac{\partial w}{\partial x}\left(1-R^{*}\right)\left[\frac{\partial u}{\partial x}+\mu \frac{\partial v}{\partial y}\right]+\right. \\
\left.+\frac{1-\mu}{2} \frac{\partial w}{\partial y}\left(1-R^{*}\right)\left(\frac{\partial u}{\partial y}+\frac{\partial v}{\partial x}\right)\right\}-\frac{E h}{1-\mu^{2}} \frac{\partial}{\partial y}\left\{\frac{\partial w}{\partial y}\left(1-R^{*}\right)\left[\mu \frac{\partial u}{\partial x}+\frac{\partial v}{\partial y}\right]+\right. \\
\left.+\frac{1-\mu}{2} \frac{\partial w}{\partial x}\left(1-R^{*}\right)\left(\frac{\partial u}{\partial y}+\frac{\partial v}{\partial x}\right)\right\} .
\end{gathered}
$$

where $q=-B \frac{\partial w}{\partial t}-B V \frac{\partial w}{\partial x}-B_{1} V^{2}\left(\frac{\partial w}{\partial x}\right)^{2}-$ is the aerodynamic pressure, determined by the Ilyushin theory [20]; $B=\frac{\aleph p_{\infty}}{V_{\infty}}, B_{1}=\frac{\aleph(\aleph+1) p_{\infty}}{4 V_{\infty}^{2}}, \aleph-$ an indicator of gas polytrope; $p_{\infty}, V_{\infty}$ the pressure and sound speed in the undisturbed gas flow, respectively.

To complete the definition of the problem, it is necessary to add boundary and initial conditions to the integro-differential equation (IDE) (1).

From equations (1), in the particular case, the Karman equations (K-L-1) can be obtained.

$$
\begin{gathered}
\frac{D}{h}\left(1-R^{*}\right) \nabla^{4} w=L(w, \Phi)-\rho \frac{\partial^{2} w}{\partial t^{2}}-\frac{B}{h} \frac{\partial w}{\partial t}-\frac{B V}{h} \frac{\partial w}{\partial x}-\frac{B_{1} V^{2}}{h}\left(\frac{\partial w}{\partial x}\right)^{2}, \\
\frac{1}{E} \nabla^{4} \Phi=-\left(1-R^{*}\right) \frac{1}{2} L(w, w),
\end{gathered}
$$

where $L(w, w)=2\left[\frac{\partial^{2} w}{\partial x^{2}} \frac{\partial^{2} w}{\partial y^{2}}-\left(\frac{\partial^{2} w}{\partial x \partial y}\right)^{2}\right]$.

In the case of a more simplified model, equations (3) are replaced by equations of the Berger type (B):

$$
D\left(1-R^{*}\right) \nabla^{4} w-D_{1} \nabla w\left(1-R^{*}\right) J_{1}(t)+\rho h \frac{\partial^{2} w}{\partial t^{2}}=q
$$

where $\quad D_{1}=\frac{E h}{2 a b\left(1-\mu^{2}\right)} ; \quad J_{1}(t)=\int_{0}^{a} \int_{0}^{b}\left[\left(\frac{\partial w}{\partial x}\right)^{2}+\left(\frac{\partial w}{\partial y}\right)^{2}\right] d x d y$. 
Table 1. Mathematical models of various theories

\begin{tabular}{|c|c|c|}
\hline No. & $\begin{array}{r}\text { Name of the theory of hereditary } \\
\text { viscoelasticity }\end{array}$ & Types of structure \\
\hline 1 & Linear & Rectangular Plate \\
& Berger & Flat and cylindrical panel \\
& Circular cylindrical shell \\
\hline 3 & Kirchhoff-Love & Cnn
\end{tabular}

\section{Discrete model and algorithm}

\subsection{Discrete model}

Present function $u(x, y, t), v(x, y, t), w(x, y, t)$ in the form of an expansion in functions $\varphi_{n m}(x, y)$, $\psi_{n m}(x, y), \theta_{n m}(x, y)$, satisfying the corresponding boundary conditions

$$
\begin{aligned}
& u(x, y, t)=\sum_{n=1}^{N} \sum_{m=1}^{M} u_{n m} \varphi_{n m}(x, y) \\
& v(x, y, t)=\sum_{n=1}^{N} \sum_{m=1}^{M} v_{n m} \psi_{n m}(x, y) \\
& w(x, y, t)=\sum_{n=1}^{N} \sum_{m=1}^{L} w_{n m} \theta_{n m}(x, y)
\end{aligned}
$$

where $u_{n m}=u_{n m}(t) v_{n m}=v_{n m}(t) w_{n m}=w_{n m}(t)$ - are the sought for functions of time; $\varphi_{n m}(x, y)$, $\psi_{n m}(x, y), \theta_{n m}(x, y)$ are known systems of coordinate functions that depend on boundary conditions.

As an example, consider hinged rectangular plate in the following systems of coordinate functions:

$$
\begin{aligned}
& \varphi_{n m}(x, y)=\cos \frac{n \pi x}{a} \sin \frac{m \pi y}{b}, \\
& \psi_{n m}(x, y)=\sin \frac{n \pi x}{a} \cos \frac{m \pi y}{b}, \\
& \theta_{n m}(x, y)=\sin \frac{n \pi x}{a} \sin \frac{m \pi y}{b} .
\end{aligned}
$$

Substituting (5) into system (1) and applying the Bubnov-Galerkin method, the system of IDE is obtained. Introducing the following dimensionless quantities $\frac{x}{a}, \frac{y}{b}, \frac{u}{h}, \frac{v}{h}, \frac{w}{h}, \frac{V_{\infty} t}{a}$, into IDE and retaining the previous notations, we get

$$
\begin{array}{r}
\sum_{n=1}^{N} \sum_{m=1}^{M} N_{1 k l n m} \ddot{u}_{n m}-\Omega\left(1-R^{*}\right)\left\{\sum_{n=1}^{N} \sum_{m=1}^{M}\left(A_{1 k l n m} u_{n m}+\frac{1+\mu}{2} B_{1 k l n m} v_{n m}\right)+\right. \\
\left.+\sum_{n, i=1}^{N} \sum_{m, r=1}^{M} D_{1 k l n m i r} w_{n m} w_{i r}\right\}=0,
\end{array}
$$




$$
\begin{gathered}
\sum_{n=1}^{N} \sum_{m=1}^{M} N_{2 k l n m} \ddot{v}_{n m}-\Omega\left(1-R^{*}\right)\left\{\sum_{n=1}^{N} \sum_{m=1}^{M}\left(\frac{1+\mu}{2} A_{2 k l n m} u_{n m}+B_{2 k l n m} v_{n m}\right)+\right. \\
\left.+\sum_{n, i=1}^{N} \sum_{m, r=1}^{M} D_{2 k l n m i r} w_{n m} w_{i r}\right\}=0, \\
\sum_{n=1}^{N} \sum_{m=1}^{M} N_{3 k l n m}\left(\ddot{w}_{n m}+M_{\lambda} \dot{w}_{n m}\right)+\left(1-R^{*}\right) \Omega \sum_{n=1}^{N} \sum_{m=1}^{M} C_{3 k l n m} w_{n m}- \\
+\sum_{n, i=1}^{N} \sum_{m, r=1}^{M} w_{n m}\left(1-R^{*}\right)\left\{A_{4 k l n m i r} u_{i r}+B_{4 k l n m i r} v_{i r}\right\} \Omega+ \\
u_{p}\left(\lambda_{1} M^{*} \sum_{n=1}^{N} \sum_{m=1}^{M} \gamma_{k l n m} w_{n m}+\frac{\aleph+1}{4} M^{*^{2}} \sum_{n, i=1}^{N} \sum_{m, r=1}^{M} \Gamma_{k l n m i r} w_{n m} w_{i r}\right)=0, \\
w_{n m}(0)=u_{\text {onm }}, \quad \dot{u}(0)=\dot{u}_{\text {onm }}, \quad \dot{v_{n m m}}(0)=v_{\text {onm }}, \quad \dot{v}(0)=\dot{v}_{o n m},
\end{gathered}
$$

where $\lambda=\frac{a}{b}, \lambda_{1}=\frac{a}{h}, \Omega=\frac{M_{E}}{1-\mu^{2}}, \quad M_{E}=\frac{E}{\rho V_{\infty}^{2}}, M_{\mathrm{p}}=\frac{p_{\infty}}{\rho V_{\infty}^{2}}, M^{*}=\frac{V}{V_{\infty}}$,

$N_{1 k l n m}, N_{2 k l n m}, N_{3 k l n m}, A_{1 k l n m}, A_{2 k l n m}, A_{4 k l n m i r}, B_{1 k l n m}, B_{2 k l n m}, B_{4 k l n m i r}, C_{3 k l n m}, D_{1 k l n m i r}, D_{2 k l n m i r}, \gamma_{k l n m}$, $\Gamma_{\text {klnmir }}$ - are dimensionless constants.

Solution of the simplified system of equations (3) is sought in the form

$$
\begin{aligned}
& w(x, y, t)=\sum_{n=1}^{N} \sum_{m=1}^{M} w_{n m} \theta_{n m}(x, y), \\
& \Phi(x, y, t)=\sum_{n=1}^{N} \sum_{m=1}^{M} \Phi_{n m} \theta_{n m}(x, y),
\end{aligned}
$$

where $w_{n m}=w_{n m}(t)$ and $\Phi_{n m}=\Phi_{n m}(t)$ - are the sought for functions of time.

Completing the Bubnov-Galerkin procedure, a system of equations with respect to $w_{n m}(t)$ and $\Phi_{n m}(t)$ is obtained; excluding $\Phi_{n m}(t)$ from this system, the following nonlinear IDE with respect to the sought for function $w_{n m}(t)$ is written:

$$
\begin{gathered}
\sum_{n=1}^{N} \sum_{m=1}^{M} N_{3 k \ln m}\left(\ddot{w}_{n m}+M_{\lambda} \dot{w}_{n m}\right)+\Omega\left(1-R^{*}\right) \sum_{n=1}^{N} \sum_{m=1}^{M} A_{k l n m} w_{n m}+ \\
+\frac{M_{E}^{2} \lambda^{4}}{\lambda_{1}^{2}} \sum_{n, i, j=1}^{N} \sum_{m, r, s=1}^{M} a_{k l n m i r j s} w_{n m}\left(1-R^{*}\right) w_{i r} w_{j s}+ \\
+\aleph M^{*} M_{p}^{2} \lambda_{1} \sum_{n=1}^{N} \sum_{m=1}^{M} \gamma_{k l n m} w_{n m}+\aleph M_{1} M^{*^{2}} \sum_{n, i=1}^{N} \sum_{m, r=1}^{M} \Gamma_{k l n m i r} w_{n m} w_{i r}=0, \\
w_{n m}(0)=w_{\text {onm }}, \quad \dot{w}(0)=\dot{w}_{\text {onm }}, \quad n=\overline{1, N} ; \quad m=\overline{1, M} ;
\end{gathered}
$$

where $A_{\mathrm{klnm}}, a_{\mathrm{klnmirjs}}, \gamma_{\mathrm{klnm}}, \Gamma_{\mathrm{klnmir}}-$ are dimensionless constants. 
Solution of equation (4) is sought in the form

$$
w(x, y, t)=\sum_{n=1}^{N} \sum_{m=1}^{M} w_{n m}(t) \theta_{n m}(x, y) .
$$

Similarly, substituting the series (9) in (4) and performing the well-known procedure of the Bubnov-Galerkin method, we obtain:

$$
\begin{gathered}
\sum_{n=1}^{N} \sum_{m=1}^{M}\left\{N_{3 l n m}\left(\ddot{w}_{n m}+M_{\lambda} \dot{w}_{n m}\right)+\left(1-R^{*}\right) \Omega A_{k l n m} w_{n m}+\right. \\
+\aleph M^{*} M_{p}^{2} \lambda_{1} \sum_{n=1}^{N} \sum_{m=1}^{M} \gamma_{k l n m} w_{n m}+\Omega \sum_{n, i, j=1}^{N} \sum_{m, r, s=1}^{M} D_{k l n m i r j s} w_{n m}\left(1-R^{*}\right) w_{i r} w_{j s}+ \\
+\aleph M_{1} M^{*^{2}} \sum_{n, i=1}^{N} \sum_{m, r=1}^{M} \Gamma_{k l n m i r} w_{n m} w_{i r}=0, \\
w_{n m}(0)=w_{\text {onm }}, \quad \dot{w}(0)=\dot{w}_{\text {onm }}, \quad n=\overline{1, N ;} ; m=\overline{1, M .}
\end{gathered}
$$

where

$$
\begin{aligned}
D_{k l n m i r j s} & =-6 J_{i r j s} \int_{0}^{1} \int_{0}^{1}\left(\theta_{n m, x x}^{\prime \prime}+\lambda^{2} \theta_{n m, y y}^{\prime \prime}\right) \theta_{k l} d x d y, \\
J_{i r j s} & =\int_{0}^{1} \int_{0}^{1}\left\{\left[\theta_{i r, x} \theta_{j s, x}\right]+\lambda^{2}\left[\theta_{i r, y} \theta_{j s, y}\right]\right\} d x d y .
\end{aligned}
$$

To solve the problem of nonlinear flutter of viscoelastic plates, described by different systems of IDE (6), (8) and (10), a numerical method based on the elimination of weakly singular features of integral and integral-differential equations is used.

\subsection{Computational algorithm}

Integrating system (6) twice with respect to $t$, it can be written in integral form; after rational transformation we eliminate singular features of the integral operator $R_{1}^{*}$. Then, assuming that $t=t_{i}, t_{i}=i \cdot \Delta t, i=1,2, \ldots(\Delta t=$ const $)$ and replacing the integrals by quadrature formulas of trapezoid to calculate $u_{i k l}=u_{k l}\left(t_{i}\right), v_{i k l}=v_{k l}\left(t_{i}\right), w_{i k l}=w_{k l}\left(t_{i}\right)$, recurrence formulas for the KoltunovRzhanitsyn kernel are obtained:

$$
u_{p k l}=u_{0 k l}+\dot{u}_{o k l} t_{p}-\sum_{j=0}^{p-1} A_{j}\left(t_{p}-t_{j}\right)\left\{M _ { E } \pi ^ { 2 } \left[\alpha_{k l}\left(u_{j k l}-\frac{A}{\alpha} \sum_{s=0}^{j} B_{s} \exp \left(-\beta t_{s}\right) u_{j-s, k l}\right)+\right.\right.
$$




$$
\begin{aligned}
& +g_{k l}\left(v_{j k l}-\frac{A}{\alpha} \sum_{s=0}^{j} B_{s} \exp \left(-\beta t_{s}\right) v_{j-s, k l}\right)+ \\
& \left.\left.+\frac{k_{g}}{\pi \lambda_{1}} \sum_{n, i=1}^{N} \sum_{m, r=1}^{M} D_{k l n m i r}\left(w_{j n m} w_{j i r}-\frac{A}{\alpha} \sum_{s=0}^{j} B_{s} \exp \left(-\beta t_{s}\right) w_{j-s, n m} w_{j-s, i r}\right)\right]\right\} \text {, } \\
& v_{p k l}=v_{0 k l}+\dot{v}_{o k l} t_{p}-\sum_{j=0}^{p-1} A_{j}\left(t_{p}-t_{j}\right)\left\{M _ { E } \pi ^ { 2 } \left[g_{k l}\left(u_{j k l}-\frac{A}{\alpha} \sum_{s=0}^{j} B_{s} \exp \left(-\beta t_{s}\right) u_{j-s, k l}\right)+\right.\right. \\
& +\beta_{k l}\left(v_{j k l}-\frac{A}{\alpha} \sum_{s=0}^{j} B_{s} \exp \left(-\beta t_{s}\right) v_{j-s, k l}\right)+ \\
& \left.\left.+\frac{\lambda k_{g}}{\pi \lambda_{1}} \sum_{n, i=1}^{N} \sum_{m, r=1}^{M} E_{k l n m i r}\left(w_{j n m} w_{j i r}-\frac{A}{\alpha} \sum_{s=0}^{j} B_{s} \exp \left(-\beta t_{s}\right) w_{j-s, n m} w_{j-s, i r}\right)\right]\right\}, \\
& w_{p k l}=\frac{1}{1+A_{p} M_{\lambda}}\left\{w_{0 k l}+\left(\dot{w_{0 k l}}+M_{\lambda} w_{0 k l}\right) t_{p}-\sum_{j=0}^{p-1} A_{j}\left(M_{\lambda} w_{j k l}-\right.\right. \\
& -\left(t_{p}-t_{j}\right)\left[\aleph M_{p}\left(2 \lambda_{1} M^{*} \sum_{n=1}^{N} \gamma_{k n} w_{j n l}+\frac{\aleph+1}{4} M^{* 2} k_{a} \sum_{n, i=1}^{N} \sum_{m, r=1}^{M} \Gamma_{k l n m i r} w_{j n m} w_{j i r}\right)+\right. \\
& +\Omega \omega_{k l}\left(w_{j k l}-\frac{A}{\alpha} \sum_{s=0}^{j} B_{s} \exp \left(-\beta t_{s}\right) w_{j-s k l}\right)- \\
& -\Omega k_{g} \sum_{n, i=1}^{N} \sum_{m, r=1}^{M} w_{j n m}\left\langle A_{k l n m i r}\left(u_{j i r}-\frac{A}{\alpha} \sum_{s=0}^{j} B_{s} \exp \left(-\beta t_{s}\right) u_{j-s i r}\right)+\right. \\
& \left.\left.+B_{k l n m i r}\left(v_{j i r}-\frac{A}{\alpha} \sum_{s=0}^{j} B_{s} \exp \left(-\beta t_{s}\right) v_{j-s, i r}\right)+C_{k l n m i r}\left(w_{j i r}-\frac{A}{\alpha} \sum_{s=0}^{j} B_{s} \exp \left(-\beta t_{s}\right) w_{j-s, i r}\right)\right] \mid\right\}, \\
& p=1,2, \ldots ; \quad k=\overline{1, N ;} \quad l=\overline{1, M} .
\end{aligned}
$$

Now numerical method for solving systems of nonlinear IDE (8) with respect to the sought for function $w_{n m}(t)$ is applied. Numerical values of the sought for function $w_{\text {inm }}=w_{n m}\left(t_{i}\right)$ at $t_{i}=i \Delta t$, $i=1,2, \ldots(\Delta t=$ const $)$ are found from the recurrence formulas:

$$
\begin{aligned}
& \sum_{n=1}^{N} \sum_{m=1}^{M} N_{k \ln m} w_{p n m}=\frac{1}{1+A_{p} M_{\lambda}}\left\{\sum_{n=1}^{N} \sum_{m=1}^{M} N_{k \ln m}\left\langle w_{0 n m}+\left(\dot{w_{0 n m}}+M_{\lambda} w_{0 n m}\right) t_{p}\right\rangle-\right. \\
& -\sum_{j=0}^{p-1} A_{j}\left(M_{\lambda} \sum_{n=1}^{N} \sum_{m=1}^{M} N_{k l n m} w_{j n m}-\left(t_{p}-t_{j}\right)\left[\aleph M _ { p } ^ { 2 } \left(\lambda_{1} M^{*} \sum_{n=1}^{N} \sum_{m=1}^{M} \gamma_{k l n m} w_{j n m}+\right.\right.\right.
\end{aligned}
$$




$$
\begin{gathered}
\left.+\frac{\aleph+1}{4} M^{* 2} \sum_{n, i=1}^{N} \sum_{m, r=1}^{M} \Gamma_{k l n m i r} w_{j n m} w_{j i r}\right)+M_{E}^{2} \beta_{1}^{2} \lambda_{1}^{2} \sum_{n=1}^{N} \sum_{m=1}^{M} E_{k l n m}\left(w_{j n m}-\right. \\
\left.-\frac{A}{\alpha} \sum_{s=0}^{j} B_{s} \exp \left(-\beta t_{s}\right) w_{j-s n m}\right)+\Omega \sum_{n=1}^{N} \sum_{m=1}^{M} A_{k l n m}\left(w_{j n m}-\frac{A}{\alpha} \sum_{s=0}^{j} B_{s} \exp \left(-\beta t_{s}\right) w_{j-s n m}\right)+ \\
+\frac{M_{E}^{2} \lambda^{4}}{\lambda_{1}^{2}} \sum_{n, i,}^{N} \sum_{\substack{m, r \\
j_{1}=1}}^{M} a_{k l n m i r r_{1} s_{1}} w_{j n m}\left(w_{j i r} w_{j j s_{1} s_{1}}-\frac{A}{\alpha} \sum_{s=0}^{j} B_{s} \exp \left(-\beta t_{s}\right) w_{j-s i r} w_{j-s j_{1} s_{1}}\right)+ \\
\left.\left.\left.+\beta_{1} M_{E}^{2} \lambda^{2} \sum_{n, i=1}^{N} \sum_{m, r=1}^{M}\left(F_{k l n m i r}+K_{k l n m i r}\right) w_{j n m}\left(w_{j i r}-\frac{A}{\alpha} \sum_{s=0}^{j} B_{s} \exp \left(-\beta t_{s}\right) w_{j-s i r}\right\rangle\right]\right)\right\} \\
w_{n m}(0)=w_{0 n m}, \mathbb{E}_{t i m}(0)=\mathbb{Q}_{n m}, p=1,2, \ldots
\end{gathered}
$$

Similarly, integrating the system (10) twice with respect to $t$, it can be written in integral form; after rational transformation we eliminate the singular features of the integral operator $R^{*}$. In this case the following recurrence formula could be obtained:

$$
\begin{gathered}
\sum_{n=1}^{N} \sum_{m=1}^{M} N_{k l n m} w_{p n m}=\frac{1}{1+A_{p} a_{1}}\left\{\sum_{n=1}^{N} \sum_{m=1}^{M} N_{k l n m}\left\langle w_{0 n m}+\left(\dot{w_{0 n m}}+a_{1} w_{0 n m}\right) t_{p}\right\rangle-\right. \\
-\sum_{j=0}^{p-1} A_{j}\left(a_{1} \sum_{n=1}^{N} \sum_{m=1}^{M} N_{k l n m} w_{j n m}-\left(t_{p}-t_{j}\right)\left[\sum_{n=1}^{N} \sum_{m=1}^{M} G_{k l n m} w_{j n m}+\right.\right. \\
+\sum_{n=1}^{N} \sum_{m=1}^{M} A_{k l n m}\left(w_{j n m}-\frac{A}{\alpha} \sum_{s=0}^{j} B_{s} \exp \left(-\beta t_{s}\right) w_{j-s, n m}\right)+ \\
\left.\left.\left.+\sum_{n, i, j_{1}=1}^{N} \sum_{m, r, s_{1}=1}^{M} D_{k l n m} w_{j n m}\left(w_{j i r} w_{j j_{1} s_{1}}-\frac{A}{\alpha} \sum_{s=0}^{j} B_{s} \exp \left(-\beta t_{s}\right) w_{j-s, i r} w_{j-s, j_{1} s_{1}}\right)\right]\right)\right\} \\
w_{n m}(0)=w_{0 n m}, \&_{i m}(0)=\&_{n n m}, p=1,2, \ldots .
\end{gathered}
$$

Owing to the proposed approach in the algorithm for numerical solution of the problem in formulas (11), (12), (13), the factor $t_{p}-t_{j}$ at $j=p$ takes the zero value, i.e. the last summand is zero. Therefore, the summation is from zero to $p-1(j=\overline{0, p-1})$.

Thus, according to a numerical method with respect to the unknowns, a system of algebraic equations is obtained. The Gauss method is used to solve the system. Based on the developed algorithm, a package of applied computer programs is created.

\section{Numeric results and discussion}

As a criterion determining the critical velocity of the flutter, a condition that at a certain velocity the amplitude of the oscillations changes according to a harmonic law (Figure. 1), is accepted. At velocity $V>V_{c r}$ there is an oscillatory motion with intensively increasing amplitudes, 
which can lead to structure destruction (Figure. 2). In the case when the flow velocity is less than the critical value $V>V_{c r}$, the amplitude of plate oscillations attenuates (Figure. 3) [27, 31-34].

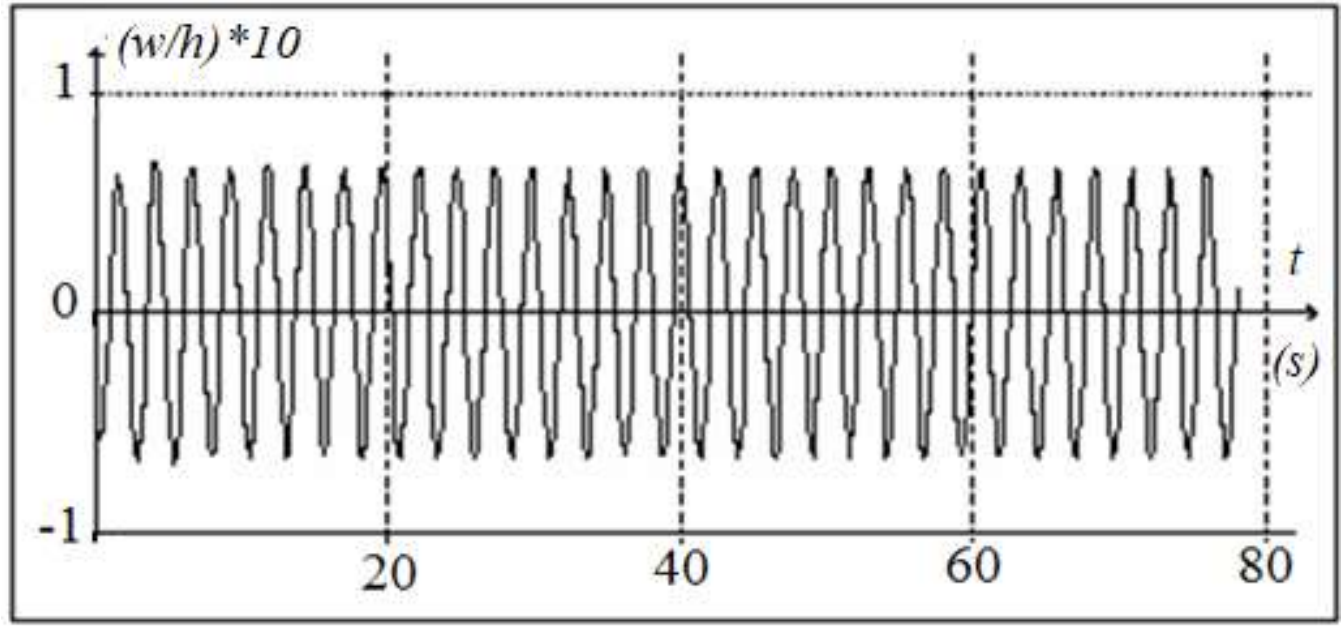

Figure. 1. Dependence of plate deflection on time $t$ at $V=V_{c r}$

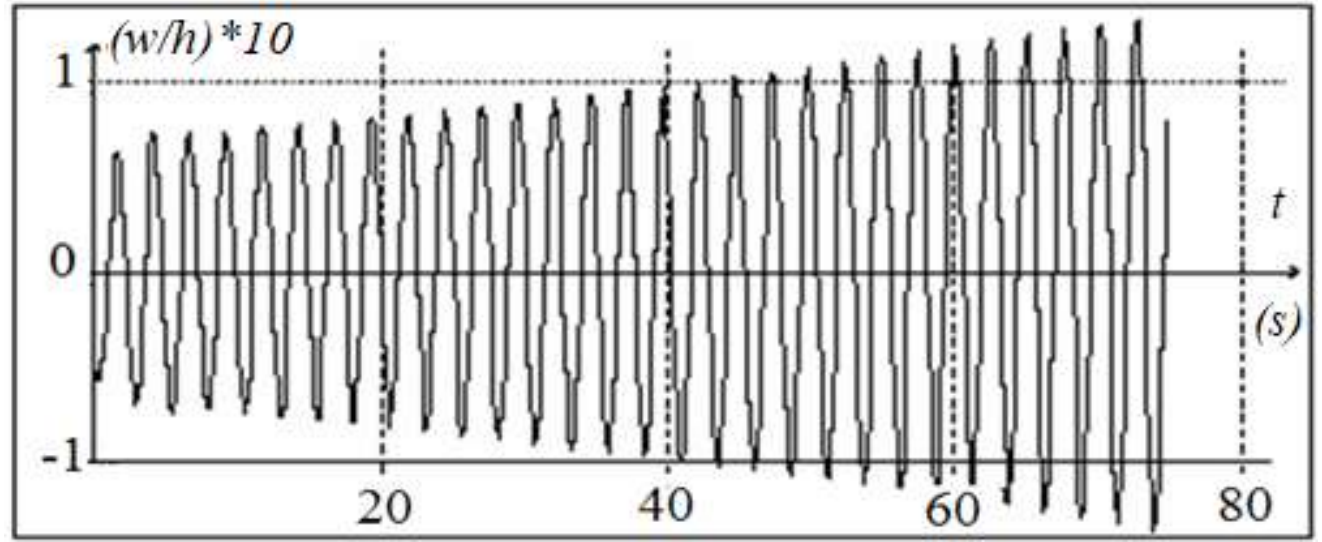

Figure. 2. Dependence of plate deflection on time $t$ at $V>V_{c r}$.

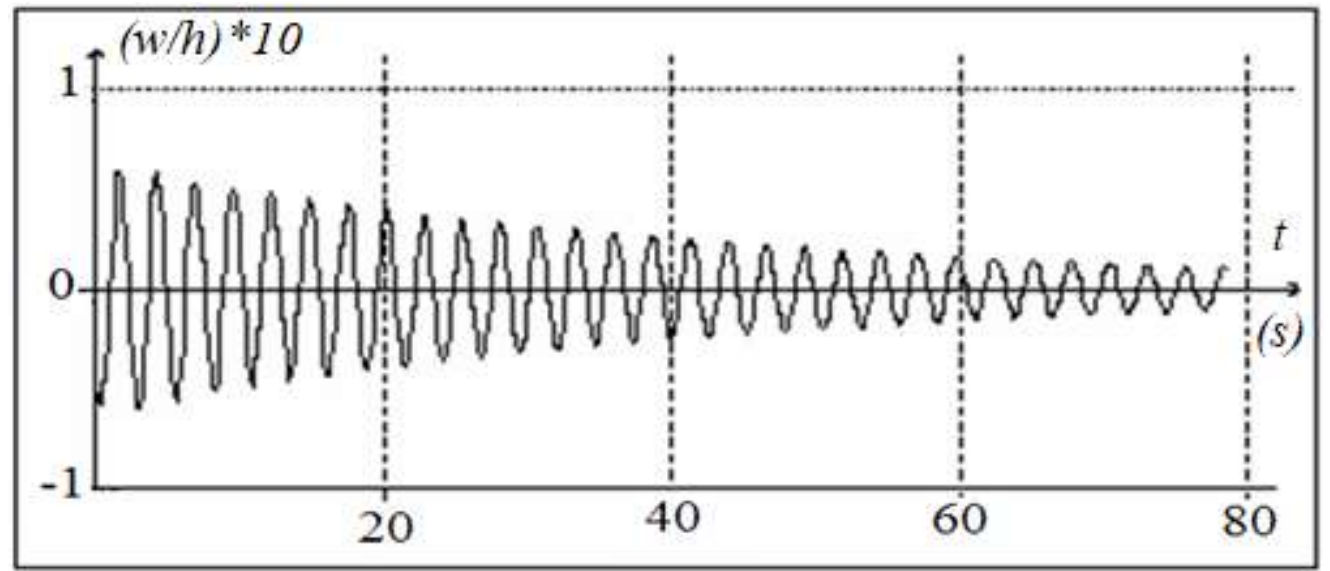

Figure. 3. Dependence of plate deflection on time $t$ at $V<V_{c r}$.

Figure. 4 shows the curves of the plate deflection versus time $t$, plotted for singularity parameters $\alpha$ : 0,1 (curve 1); 0,4 (curve 2 ). The effect of the singularity parameter $\alpha$ in this case is quite marked and results in 30\%-40\% decrease in amplitude and frequency of oscillations. 


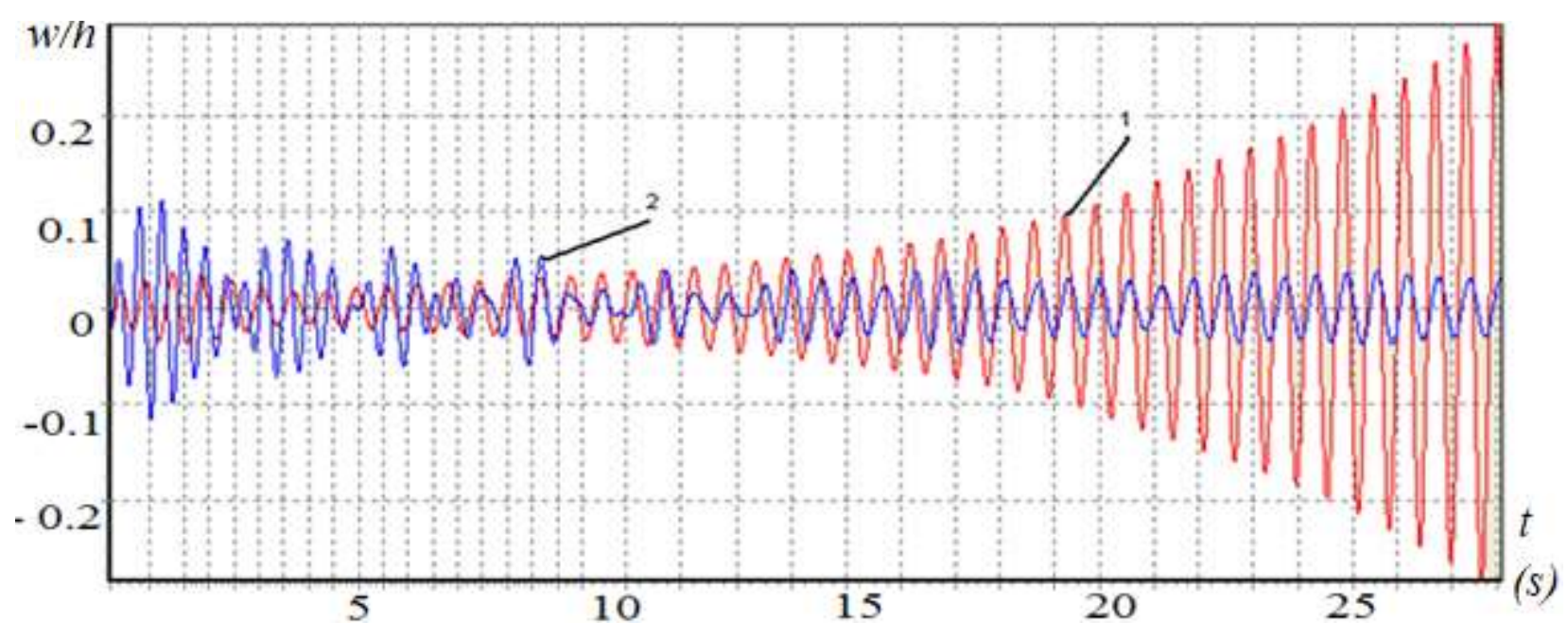

Figure. 4. Dependence of plate deflection on time $t$ at rheological parameter $\alpha$ : 0,1 (curve 1); 0,4 (curve 2).

Thus, we can conclude that the singularity parameter $\alpha$ affects not only the oscillations of viscoelastic systems, but also the critical flutter velocity. Consequently, consideration of this influence in the design of aviation elements and units is important, since the smaller the singularity parameter of structure material, the more intensive the dissipative processes in these structures.

The influence of the parameter $\lambda$ on amplitude-frequency characteristics of a viscoelastic plate is studied at velocity $V=545 \mathrm{~m} / \mathrm{s}$ (Figure. 5). At $\lambda=1,5$ there is a harmonic oscillation, i.e. the flow velocity is critical. At $\lambda=1,2$, the amplitude of oscillations increases rapidly.

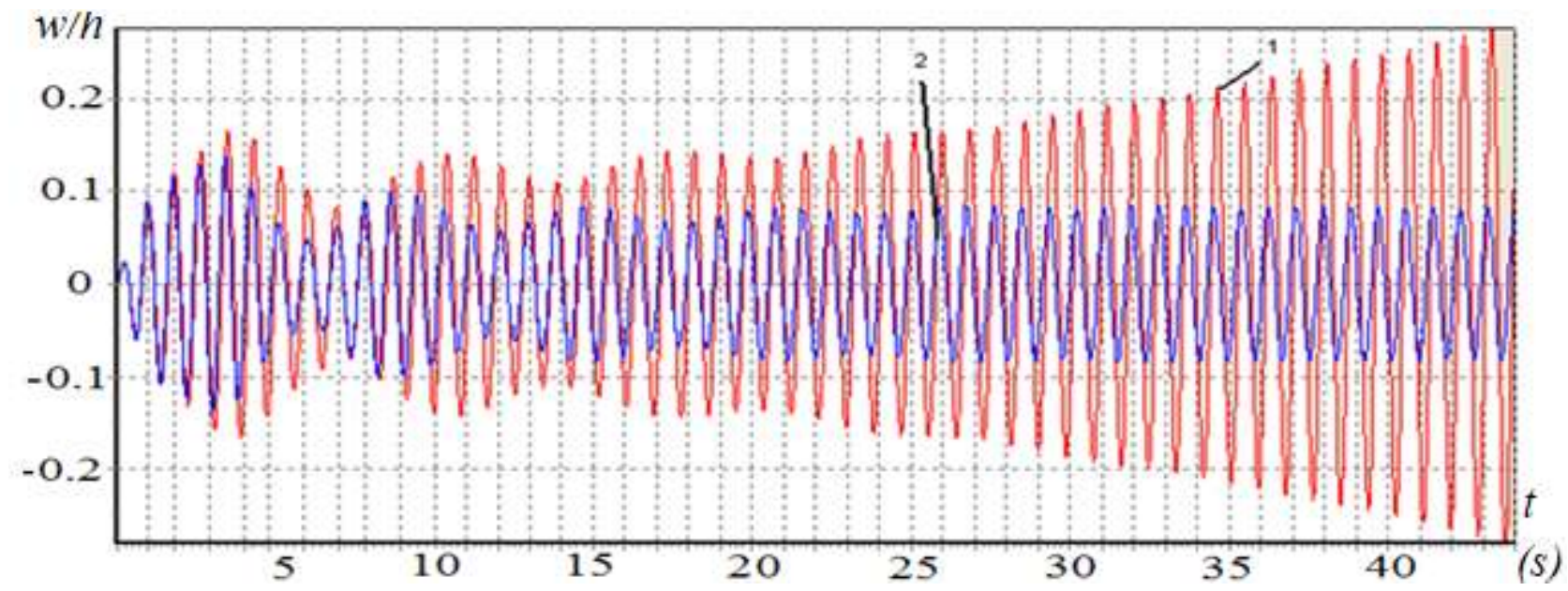

Figure. 5. Dependence of plate deflection on time $t$ at $\lambda: 1,2$ (curve 1); 1,5 (curve 2).

Figure 6 shows the graphs of deflections at the center of the plate $(x=0.5, y=0.5)$ versus time at different values of the parameter $\lambda_{1}: 60$ (curve 1), 120 (curve 2). As seen from the graphs, as the plate thickness decreases (with increasing of the parameter $\lambda_{1}$ ), the amplitude of oscillations increases with time and the flutter motion occurs. 


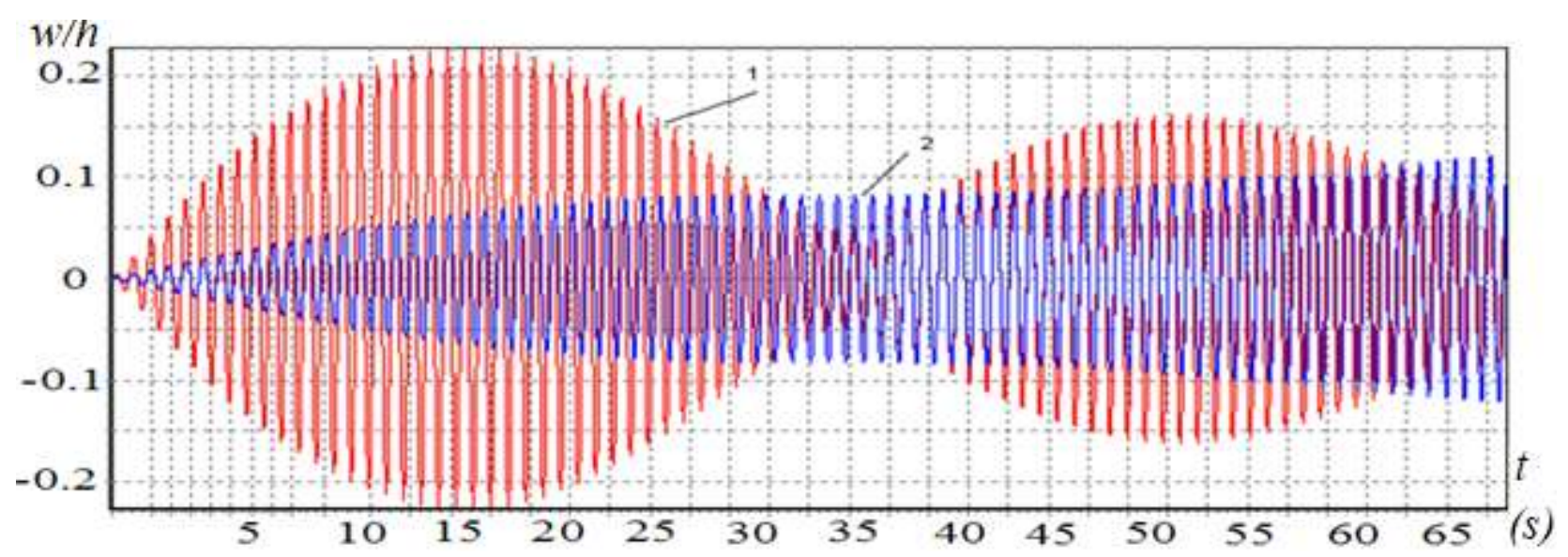

Figure. 6. Dependence of deflections in the center of the plate $(x=0,5 ; y=0,5)$ on time $t$ at values of the parameter $\lambda_{1}: 60$ (curve 1), 120 (curve 2).

Results of calculations are presented in Table 2 at $N=5, M=1$. In the last three columns of the table the critical flutter velocities, determined by formulas (1), (3) and (4), are given.

Table 2. Comparison of results obtained from various theories

\begin{tabular}{|c|c|c|c|c|c|c|c|}
\hline \multirow{2}{*}{$\mathbf{A}$} & \multirow{2}{*}{$\alpha$} & \multirow{2}{*}{$\beta$} & \multirow{2}{*}{$\lambda$} & \multirow{2}{*}{$\lambda_{1}$} & \multicolumn{3}{|c|}{$V_{c r}$} \\
\hline & & & & & B & K-L-1 & K-L-2 \\
\hline 0,0 & \multirow{2}{*}{0,25} & \multirow{2}{*}{0,05} & \multirow{2}{*}{1} & \multirow{2}{*}{220} & 1003 & 1009 & 1025 \\
\hline 0,1 & & & & & 537,2 & 542 & 549 \\
\hline \multirow{3}{*}{0,1} & 1 & \multirow{3}{*}{0,05} & \multirow{3}{*}{1} & \multirow{3}{*}{220} & 993,14 & 997 & 1012 \\
\hline & 0,5 & & & & 697,34 & 705 & 719 \\
\hline & 0,15 & & & & 412,42 & 420 & 434 \\
\hline \multirow{2}{*}{0,001} & \multirow{2}{*}{0,2} & 0,1 & \multirow{2}{*}{2,2} & \multirow{2}{*}{250} & 952,5 & 971 & 1043 \\
\hline & & 0,2 & & & 944,5 & 964 & 1036 \\
\hline \multirow{3}{*}{0,1} & \multirow{3}{*}{0,25} & \multirow{3}{*}{0,05} & 3,2 & \multirow{3}{*}{300} & 1288 & 1302 & 1575 \\
\hline & & & 2,5 & & 1017 & 1030 & 1196 \\
\hline & & & 2,2 & & 724 & 736 & 829 \\
\hline \multirow{2}{*}{0,001} & \multirow{2}{*}{0,2} & \multirow{2}{*}{0,05} & \multirow{2}{*}{2,2} & 300 & 826 & 839 & 941 \\
\hline & & & & 350 & 651 & 709 & 752 \\
\hline
\end{tabular}

Comparison of solutions is carried out by determining the critical velocity of plate flutter (Table 2). In elastic case for a square plate, the flutter velocities found from formulas (1), (3) and (4) are: $1025 \mathrm{~m} / \mathrm{s}, 1009 \mathrm{~m} / \mathrm{s}$ and $1003 \mathrm{~m} / \mathrm{s}$. The difference in critical velocities is negligible. In viscoelastic case these values are: $549 \mathrm{~m} / \mathrm{s}, 542 \mathrm{~m} / \mathrm{s}$ and $537.2 \mathrm{~m} / \mathrm{s}$. The viscosity parameter $A$ reduces the flutter velocity by two times. In calculations the following values of the constants are taken: $\mu=0,32 ; V_{\infty}=340 \mathrm{~m} / \mathrm{s} ; p_{\infty}=1,014 \mathrm{~kg} / \mathrm{cm}^{2} ; \aleph=1,4$.

Now the effect of plate elongation $\lambda$ on the flutter velocity is investigated. With an increase in parameter $\lambda$ from 2,2 to 3,2 , the difference in critical velocities, determined by formulas (1), 
(3) and (4), also increases. For example, at $\lambda=2,2$ the flutter velocity determined by formula (1) is $1575 \mathrm{~m} / \mathrm{s}$, by formula (2) $-1302 \mathrm{~m} / \mathrm{s}$ and by formula (3) $-1288 \mathrm{~m} / \mathrm{s}$. The difference in these velocities is essential.

\section{Conclusions}

On the basis of the results obtained, we can conclude that the most adequate theory for investigating a wide class of problems of the hereditary theory of viscoelasticity is the geometric nonlinear Kirchhoff-Love theory with account of elastic waves propagation.

It is shown that, for nonlinear problems of dynamics of the hereditary theory of viscoelasticity, the simplification method (Bubnov-Galerkin) of spatial models is the most effective one to reduce the dimensionality and obtain resolving models that ensure their effective numerical realization in engineering calculations.

It is stated that an account of viscoelastic properties of plate material leads to $40-60 \%$ decrease in the critical flutter velocity.

In conclusion, it should be noted that in the case of viscoelastic square plate, the results obtained using the above theories coincide. However, at certain geometric parameters of the plate, the results obtained using these theories differ significantly from each other. In this statement of the problem, the most adequate theory is the classical Kirchhoff-Love theory with account of elastic waves propagation.

\section{References}

1. Bogdan I.E., Liaosha S.T., Païdoussis M.P. Coherent Structures and Their Influence on the Dynamics of Aeroelastic Panels. International Journal of Non-Linear Mechanics, 2004, vol. 39, pp. 977-991.

2. Tubaldi E., Alijani F., Amabili M. Non-linear Vibrations and Stability of a Periodically Supported Rectangular Plate in Axial Flow. International Journal of Non-Linear Mechanics, 2014, vol.66, pp.54-65.

3. Tubaldi E., Amabili M., Alijani F. Nonlinear Vibrations of Plates in Axial Pulsating Flow. Journal of Fluids and Structures, 2015, vol.56, pp.33-55.

4. Baghdasaryan G.Y., Mikilyan M.A., Saghoyan R.O., Cestino E., Frulla G., Marzocca P. Nonlinear LCO "Amplitude-frequency" Characteristics for Plates Fluttering at Supersonic Speeds. International Journal of Non-Linear Mechanics, 2015, vol.77, pp. 51-60.

5. Liviu L., Gianfranco C., Piergiovanni M. Implications of Cubic Physical/aerodynamic Nonlinearities on the Character of the Flutter Instability Boundary. International Journal of NonLinear Mechanics, 2015, vol.38, pp.173-199.

6. Eftekhari S.A., Bakhtiari-Nejad F., Dowell E.H. Damage Detection of an Aeroelastic Panel using Limit Cycle Oscillation Analysis. International Journal of Non-Linear Mechanics, 2014, vol.58, pp.99-110 
7. Higuchi K., Dowell E.H. Dynamic Stability of a Completely Free Plate Subjected to a Controlled Non-conservative Follower Force. Journal of Sound and Vibration, 1989, vol.132, pp.115-128.

8. Nezami M., Gholami B. Optimal locations of piezoelectric patches for supersonic flutter control of honeycomb sandwich panels, using the NSGA-II method. Smart Mater. Struct. 2016, vol.25, pp. 035043

9. Matter Y.S., Darabseh T.T., Mourad A.H.I. Effect of engine location on flutter speed and frequency of a tapered viscoelastic wing. IOP Conference Series: Materials Science and Engineering, 2018, vol.370, pp.012014.

10. Perez M., Boisseau S., Gasnier P., Willemin J., Reboud J. L. An electret-based aeroelastic flutter energy harvester. Smart Mater. Struct., 2015, vol.24, pp. 035004.

11. Shih-Yao Kuo, Le-Chung Shiau and Chin-Hsin Lai. Flutter of buckled shape memory alloy reinforced laminates. Smart Mater. Struct., 2012, V.21, pp.035020.

12. Zhi-Guang Song and Feng-Ming Li. Active aeroelastic flutter analysis and vibration control of supersonic beams using the piezoelectric actuator/sensor pairs. Smart Mater. Struct., 2011, vol.20, pp.055013.

13. Matthew Bryant, Eric Wolff and Ephrahim Garcia. Aeroelastic flutter energy harvester design: the sensitivity of the driving instability to system parameters. Smart Mater. Struct. 2011, vol.20, pp.125017.

14. Kreifels L., Hornsby W.A., Weikl A., Peeters A.G.Influence of magnetic flutter on tearing growth in linear and nonlinear theory Plasma Phys. Control. Fusion, 2018, vol.60, pp.065004.

15. Seyyed M Hasheminejad, Nezami M., Aryaee Panah M. E. Supersonic flutter suppression of electrorheological fluid-based adaptive panels resting on elastic foundations using sliding mode control. Smart Mater. Struct. 2012, vol.21. pp.045005.

16. Landa P.S., and McClintock P.V.E. Æolian tones and stall flutter of lengthy objects in fluid flows. J. Phys. A: Math. Theor., 2010, vol.43, pp.375101.

17. Bao Chun-Yu, Tang Chao, Yin Xie-Zhen, Lu Xi-Yun. Flutter of Finite-Span Flexible Plates in Uniform Flow. Chinese Physics Letters 2010, vol.27, pp.064601.

18. Farbod Alijani, Marco Amabili. Non-linear Vibrations of Shells: A literature review from 2003 to 2013. International Journal of Non-Linear Mechanics, 2014, V.58, pp.233-257.

19. Matyash V.I. Flutter of a Viscoelastic Plate. Mech Polymer, 1971, no 6. pp.1077-1083. (in Russian).

20. Larionov G.S. Nonlinear Flutter of Viscoelastic Plates. Russ Mech Solids, 1974, no. 4, pp.95-100. (in Russian).

21. Permoon V., Haddadpour H., Javadi M. Nonlinear Vibration of Fractional Viscoelastic Plate: Primary, Subharmonic, and Super harmonic Response. International Journal of NonLinear Mechanics, 2018, vol.99, pp.154-164. 
22. Mouafo Teifouet, Armand Robinson, Sarp Adali, Non-conservative Stability of Viscoelastic Rectangular Plates with Free Edges under Uniformly Distributed Follower Force. International Journal of Mechanical Sciences, 2016, V.107, pp.150-159.

\section{https://doi.org/10.1016/j.ijmecsci.2015.12.029}

23. Bland D.R. The theory of linear viscoelasticity. Pergamum Press, Oxford, 1960.

24. Ilyushin A.A. Theory of Thermoviscoelasticity. Fizmatlit, Moscow, 2007. (in Russian).

25. Eshmatov B.Kh., Eshmatov Kh., Khodzhaev D.A., Nonlinear Flutter of Viscoelastic Rectangular Plates and Cylindrical Panels of a Composite with a Concentrated Mass. Journal of Applied Mechanics and Technical Physics, 2013, V.54, pp.578-587.

26. Badalov F.B. Methods for Solving Integral and Integro-differential Equations of the Hereditary Theory of Viscoelasticity. Mekhnat, Tashkent, 1987. (in Russian).

27. Khudayarov B.A. Numerical Study of the Dependence of the Critical Flutter Velocity and Time of a Plate on Rheological Parameters. International Applied Mechanics, 2008, vol.44, pp.676-682.

28. Badalov F.B., Eshmatov Kh., Yusupov M. Some Methods of Solution of the Systems of Integro-differential Equations in Problems of Viscoelasticity. Applied Mathematics and Mechanics, 1987, vol.51, pp.867-871. (in Russian).

29. Grigolyuk E.I., Mamai V.I. Nonlinear Stress of Thin-walled Structures. Nauka, Moscow, 1997. (in Russian).

30. Ilyushin A.A., Kiyko I.A. Plane sections law in supersonic aerodynamics and panel flutter problem. Mechanics of Solids, 1995, vol.6, pp.138-142. (in Russian).

31. Khudayarov B.A. Numerical Analysis of Nonlinear Flutter of Viscoelastic Plates. International Applied Mechanics, 2005, V.41, pp.538-542.

32. Khudayarov B.A., Bandurin N.G. Numerical Investigation of Nonlinear Vibrations of Viscoelastic Plates and Cylindrical Panels in a Gas Flow. Journal of Applied Mechanics and Technical Physics, 2007, vol.48, pp.279-284.

33. Khudayarov B.A. Flutter of Viscoelastic Plate in a Supersonic Gas Flow. International Applied Mechanics, 2010, vol.46, pp.455-460.

34. Badalov F.B., Khudayarov B.A., Abdukarimov A. Effect of the Hereditary Kernel on the Solution of Linear and Nonlinear Dynamic Problems of Hereditary Deformable Systems. Journal of Machinery Manufacture and Reliability, 2007, vol.36, pp.328-335. 
УдК 539.3

\title{
Вычислительные эксперименты для оценки подходов к моделированию движения вязкоупругих пластинок, построенных на основе различных теорий
}

Худаяров Б.А.,**

\author{
bakht-flpo@yandex.ru \\ ${ }^{1}$ Ташкентский институт ирригации и механизации \\ сельского хозяйства, Ташкент, Узбекистан
}

Ключевые слова: математическое моделирование, вязкоупругость, численный метод, вычислительный алгоритм, интегро-дифференциальное уравнение, флаттер, критическая скорость

Математическое и компьютерное моделирование флаттера элементов и узлов конструкции летательного аппарата представляет собой актуальную научную проблему, изучение которой стимулировалось выходом из строя самолетных конструкций, деталей космических и реактивных двигателей. Ввиду сложности явления флаттера элементов летательных аппаратов во многих исследованиях используются упрощающие предположения. Однако эти предположения, как правило, имеют столько ограничений, что математическая модель перестает точно отражать реальные условия. Поэтому результаты теоретических и экспериментальных исследований часто не совпадают.

В настоящее время задача панельного флаттера является весьма актуальной. Совершенствование характеристик как военных, так и гражданских самолётов неизбежно требует уменьшения их массы, а, следовательно, и жёсткости панелей обшивки, что повышает возможность возникновения панельного флаттера. Активно обсуждаются концепции создания самолётов с изменяемой формой, что также неизбежно приводит к уменьшению толщины обшивки. Наконец, использование новых материалов и, в частности, композитов меняет физические свойства панелей и также может привести к возникновению флаттера.

Отмеченная выше научная проблема дает основание утверждать, что разработка адекватных математических моделей, численных методов и алгоритмов решения нелинейных интегро-дифференциальных уравнений динамических задач наследственной теории вязкоупругости является актуальной.

В связи с этим актуальное значение приобретает разработка математических моделей отдельных элементов летательных аппаратов, выполненных из композиционных материалов. 
В работе на основе интегральных моделей, построены обобщенные математические модели нелинейных задач о флаттере вязкоупругих изотропных пластин, обтекаемых сверхзвуковым потоком газа. Для исследования колебательных процессов пластинок предлагается численный алгоритм решения нелинейных интегро-дифференциальных уравнений с сингулярными ядрами. На основе разработанного вычислительного алгоритма создан комплекс прикладных программ. Численно исследовано влияние параметра сингулярности в ядрах наследственности на колебания конструкций, обладающих вязкоупругими свойствами. В широком диапазоне изменения различных параметров пластины определены критические скорости флаттера. Сравниваются численное решений задачи флаттера вязкоупругих пластин по различным моделям. Показано, что наиболее адекватной теорией для исследования широкого класса задач наследственной теории вязкоупругости является геометрическая нелинейная теория Кирхгоффа-Лява с учетом распространения упругих волн. Установлено, что учет вязкоупругих свойств материала пластин приводит к уменьшению критической скорости флаттера на 40 - 60\%.

\section{Список литературы}

1. Bogdan I.E., Liaosha S.T., Païdoussis M.P. Coherent Structures and Their Influence on the Dynamics of Aeroelastic Panels. International Journal of Non-Linear Mechanics, 2004, vol. 39, pp. 977-991.

2. Tubaldi E., Alijani F., Amabili M. Non-linear Vibrations and Stability of a Periodically Supported Rectangular Plate in Axial Flow. International Journal of Non-Linear Mechanics, 2014, vol.66, pp.54-65.

3. Tubaldi E., Amabili M., Alijani F. Nonlinear Vibrations of Plates in Axial Pulsating Flow. Journal of Fluids and Structures, 2015, vol.56, pp.33-55.

4. Baghdasaryan G.Y., Mikilyan M.A., Saghoyan R.O., Cestino E., Frulla G., Marzocca P. Nonlinear LCO "Amplitude-frequency" Characteristics for Plates Fluttering at Supersonic Speeds. International Journal of Non-Linear Mechanics, 2015, vol.77, pp. 51-60.

5. Liviu L., Gianfranco C., Piergiovanni M. Implications of Cubic Physical/aerodynamic Nonlinearities on the Character of the Flutter Instability Boundary. International Journal of NonLinear Mechanics, 2015, vol.38, pp.173-199.

6. Eftekhari S.A., Bakhtiari-Nejad F., Dowell E.H. Damage Detection of an Aeroelastic Panel using Limit Cycle Oscillation Analysis. International Journal of Non-Linear Mechanics, 2014, vol.58, pp.99-110

7. Higuchi K., Dowell E.H. Dynamic Stability of a Completely Free Plate Subjected to a Controlled Non-conservative Follower Force. Journal of Sound and Vibration, 1989, vol.132, pp.115-128.

8. Nezami M., Gholami B. Optimal locations of piezoelectric patches for supersonic flutter control of honeycomb sandwich panels, using the NSGA-II method. Smart Mater. Struct. 2016, vol.25, pp. 035043 
9. Matter Y.S., Darabseh T.T., Mourad A.H.I. Effect of engine location on flutter speed and frequency of a tapered viscoelastic wing. IOP Conference Series: Materials Science and Engineering, 2018, vol.370, pp.012014.

10. Perez M., Boisseau S., Gasnier P., Willemin J., Reboud J. L. An electret-based aeroelastic flutter energy harvester. Smart Mater. Struct., 2015, vol.24, pp. 035004.

11. Shih-Yao Kuo, Le-Chung Shiau and Chin-Hsin Lai. Flutter of buckled shape memory alloy reinforced laminates. Smart Mater. Struct., 2012, V.21, pp.035020.

12. Zhi-Guang Song and Feng-Ming Li. Active aeroelastic flutter analysis and vibration control of supersonic beams using the piezoelectric actuator/sensor pairs. Smart Mater. Struct., 2011, vol.20, pp.055013.

13. Matthew Bryant, Eric Wolff and Ephrahim Garcia. Aeroelastic flutter energy harvester design: the sensitivity of the driving instability to system parameters. Smart Mater. Struct. 2011, vol.20, pp.125017.

14. Kreifels L., Hornsby W.A., Weikl A., Peeters A.G.Influence of magnetic flutter on tearing growth in linear and nonlinear theory Plasma Phys. Control. Fusion, 2018, vol.60, pp.065004.

15. Seyyed M Hasheminejad, Nezami M., Aryaee Panah M. E. Supersonic flutter suppression of electrorheological fluid-based adaptive panels resting on elastic foundations using sliding mode control. Smart Mater. Struct. 2012, vol.21. pp.045005.

16. Landa P.S., and McClintock P.V.E. Æolian tones and stall flutter of lengthy objects in fluid flows. J. Phys. A: Math. Theor., 2010, vol.43, pp.375101.

17. Bao Chun-Yu, Tang Chao, Yin Xie-Zhen, Lu Xi-Yun. Flutter of Finite-Span Flexible Plates in Uniform Flow. Chinese Physics Letters 2010, vol.27, pp.064601.

18. Farbod Alijani, Marco Amabili. Non-linear Vibrations of Shells: A literature review from 2003 to 2013. International Journal of Non-Linear Mechanics, 2014, V.58, pp.233-257.

19. Matyash V.I. Flutter of a Viscoelastic Plate. Mech Polymer, 1971, no 6. pp.1077-1083. (in Russian).

20. Larionov G.S. Nonlinear Flutter of Viscoelastic Plates. Russ Mech Solids, 1974, no. 4, pp.95-100. (in Russian).

21. Permoon V., Haddadpour H., Javadi M. Nonlinear Vibration of Fractional Viscoelastic Plate: Primary, Subharmonic, and Super harmonic Response. International Journal of NonLinear Mechanics, 2018, vol.99, pp.154-164.

22. Mouafo Teifouet, Armand Robinson, Sarp Adali, Non-conservative Stability of Viscoelastic Rectangular Plates with Free Edges under Uniformly Distributed Follower Force. International Journal of Mechanical Sciences, 2016, V.107, pp.150-159.

https://doi.org/10.1016/j.ijmecsci.2015.12.029

23. Bland D.R. The theory of linear viscoelasticity. Pergamum Press, Oxford, 1960.

24. Ilyushin A.A. Theory of Thermoviscoelasticity. Fizmatlit, Moscow, 2007. (in Russian). 
25. Eshmatov B.Kh., Eshmatov Kh., Khodzhaev D.A., Nonlinear Flutter of Viscoelastic Rectangular Plates and Cylindrical Panels of a Composite with a Concentrated Mass. Journal of Applied Mechanics and Technical Physics, 2013, V.54, pp.578-587.

26. Badalov F.B. Methods for Solving Integral and Integro-differential Equations of the Hereditary Theory of Viscoelasticity. Mekhnat, Tashkent, 1987. (in Russian).

27. Khudayarov B.A. Numerical Study of the Dependence of the Critical Flutter Velocity and Time of a Plate on Rheological Parameters. International Applied Mechanics, 2008, vol.44, pp.676-682.

28. Badalov F.B., Eshmatov Kh., Yusupov M. Some Methods of Solution of the Systems of Integro-differential Equations in Problems of Viscoelasticity. Applied Mathematics and Mechanics, 1987, vol.51, pp.867-871. (in Russian).

29. Grigolyuk E.I., Mamai V.I. Nonlinear Stress of Thin-walled Structures. Nauka, Moscow, 1997. (in Russian).

30. Ilyushin A.A., Kiyko I.A. Plane sections law in supersonic aerodynamics and panel flutter problem. Mechanics of Solids, 1995, vol.6, pp.138-142. (in Russian).

31. Khudayarov B.A. Numerical Analysis of Nonlinear Flutter of Viscoelastic Plates. International Applied Mechanics, 2005, V.41, pp.538-542.

32. Khudayarov B.A., Bandurin N.G. Numerical Investigation of Nonlinear Vibrations of Viscoelastic Plates and Cylindrical Panels in a Gas Flow. Journal of Applied Mechanics and Technical Physics, 2007, vol.48, pp.279-284.

33. Khudayarov B.A. Flutter of Viscoelastic Plate in a Supersonic Gas Flow. International Applied Mechanics, 2010, vol.46, pp.455-460.

34. Badalov F.B., Khudayarov B.A., Abdukarimov A. Effect of the Hereditary Kernel on the Solution of Linear and Nonlinear Dynamic Problems of Hereditary Deformable Systems. Journal of Machinery Manufacture and Reliability, 2007, vol.36, pp.328-335. 